\title{
Mononeuropatia Múltipla como forma de apresentação da Granulomatose Eosinofílica com Poliangeíte
}

\author{
Eosinophilic Granulomatosis with Polyangiitis \\ presenting as Mononeuritis Multiplex
}

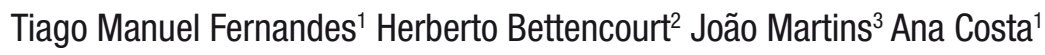 \\ ${ }^{\top}$ Serviço de Medicina Interna, Hospital Pedro Hispano \\ ${ }^{2}$ Serviço de Anatomia Patológica, Hospital Pedro Hispano \\ ${ }^{3}$ Serviço de Neurologia, Hospital Pedro Hispano
}

\begin{abstract}
Resumo
A Granulomatose Eosinofilica com Poliangeíte (EGPA), previamente denominada Síndrome de Churg-Strauss, é uma vasculite associada ao anticorpo anti-citoplasma dos neutrófilos (ANCA) que atinge vasos de pequeno calibre. Os autores descrevem o caso de uma mulher com instalação subaguda de parestesias, disestesias, paraparésia crural a impossibilitar a marcha e lesões purpúricas no tornozelo. A electromiografia mostrou mononeuropatia múltipla com envolvimento dos nervos Mediano esquerdo, Cubital e Femoral direitos. Estudo analítico com eosinofilia e ANCA positivo. A biópsia cutânea mostrou vasculite necrotizante e infiltrado eosinofílico. Cumpre a definição de Chapel Hill Conference Consensus e reúne os critérios do American College of Rheumatology pelo que foi assumido o diagnóstico de EGPA. Iniciou corticoterapia e ciclofosfamida, com melhoria clínica e laboratorial. Este caso clínico ilustra a importância do reconhecimento do padrão da neuropatia periférica na apresentação desta entidade rara que pode ser incapacitante se houver atraso no diagnóstico e tratamento.

Palavras-chave: Síndrome de Churg-Strauss; Angiite Granulomatosa Alérgica; Mononeuropatia Múltipla; Vasculite Associada a ANCA; Anticorpo Anti-Citoplasma de Neutrófilo; Eosinofilia.
\end{abstract}

\section{Introdução}

A Granulomatose Eosinofílica com Poliangeíte (EGPA), previamente denominada Síndrome de Churg-Strauss, segundo a Conferência de Consenso de Chapel Hill (CHCC) pertence ao grupo das vasculites associadas ao anticorpo anti-citoplasma dos neutrófilos (ANCA), caracterizando-se por uma inflamação eosinofílica granulomatosa e por uma vasculite necrotizante sistémica pauci-imune que afecta os vasos de pequeno calibre ${ }^{1}$. Foram propostos vários critérios de diagnóstico ao longo dos anos, mas não existem critérios validados, sendo os da American College of Rheumatology2 (ACR) os mais usados em associação com a definição da CHCC.

Relativamente ao ANCA não está esclarecido de que forma está envolvido na fisiopatologia da EGPA, no entanto sabe-se que está presente em 30-50\% dos doentes, habitualmente 0 anticorpo anti-mieloperoxidase (MP0), um subgrupo do ANCA detectado por ensaio de imunoabsorção enzimática

\begin{abstract}
Eosinophilic Granulomatosis with Polyangiitis (EGPA), formerly known as Churg-Strauss Syndrome, is a anti-neutrophil cytoplasmic antibody (ANCA) associated vasculites affecting small vessels. We describe a women with subacute complaints of paresthesias, disesthesias, crural paraparesis with lost of gait and purpuric lesions on her ankle. Electromyogram revealed multiplex mononeuropathy with left median nerve, right ulnar and femoral nerves involvement. Laboratory analysis with eosinophilia and positive ANCA. She fulfilled the Chapel Hill Conference Consensus definition and the criteria of American College of Rheumatology for EGPA. Corticosteroids and cyclophosphamide were begun with good clinical and laboratorial response. This report ilustrates the importance of identifying the neuropatic pattern as initial manifestation of this rare condition that can cause significant disability if there is delay on the diagnosis and treatment. Keywords: Churg-Strauss Syndrome; Eosinophilic Granulomatous Vasculitis; Mononeuropathy Multiplex; ANCA-Associated Vasculitis; Anti-Neutrophil Cytoplasmic Antibody; Eosinophilia.
\end{abstract}

(ELISA) e que produz um padrão perinuclear (p-ANCA) na imunofluorescência ${ }^{3,4}(\mathrm{FE})$.

A prevalência estimada da EGPA é de 14-17.8 casos/1 000 000 habitantes ${ }^{4,5}$, com uma incidência anual de 1-2 novos casos/1 000000 de habitantes ${ }^{6}$. A taxa de sobrevida aos 5 anos $^{7}$ é de $60-97 \%$. Classicamente são descritas 3 fases clínicas: a prodrómica dominada pela asma; a fase eosinofílica caracterizada pela eosinofilia periférica e infiltrativa; e a fase vasculítica geralmente associada a sintomas constitucionais. A asma parece ser a característica clínica mais distinta da EGPA estando presente em praticamente todos os casos. As outras manifestações clínicas mais frequentes são: a neuropatia periférica, a sinusite/polipose nasal, as lesões cutâneas e os infiltrados pulmonares ${ }^{3,4,8}$.

A neuropatia periférica está presente em $51 \%$ a $93 \%$ dos casos de EGPA $3,4,8$ e manifesta-se como mononeuropatia múltipla ou polineuropatia periférica ${ }^{9-11}$. Os sintomas mais comuns são a dor neuropática e as parestesias. Patofisiologicamente, a lesão neuronal é primariamente axonal de 
causa vasculítica, e os nervos mais envolvidos são os dos membros inferiores ${ }^{9-11}$. 0 tratamento geralmente envolve administração de corticosteróides e outros imunossupressores $^{12,13}$.

Os autores descrevem um caso clínico de uma doente com manifestações neurológicas incapacitantes sob a forma de mononeuropatia múltipla, cuja investigação etiológica revelou tratar-se de EGPA.

\section{Caso clínico}

Mulher de 66 anos, apresenta-se no Serviço de Urgência com quadro subagudo (2 semanas de evolução) caracterizado inicialmente por parestesias, disestesias e falta de força distalmente no membro superior esquerdo com desenvolvimento posterior de diminuição da força proximal nos membros inferiores a impossibilitar a marcha autónoma. Entretanto desenvolve febre, astenia e lesões de cor violácea na perna esquerda.

Dos antecedentes destaca-se sinusite crónica, polipose nasal e asma diagnosticada em idade adulta.

Ao exame neurológico com hipostesia, disestesias na mão e parésia distal do membro superior esquerdo, sugestivo de disfunção de nervo Mediano, e paraparésia proximal de ambos membros inferiores com hipostesia na coxa e região antero-medial da perna direita. No restante exame objectivo com lesões purpúricas no tornozelo esquerdo que não desapareciam à digitopressão (Fig. 1), auscultação pulmonar com crepitações dispersas bilateralmente, sem alterações na auscultação cardíaca.

Fez electromiografia que mostrou múltiplas mononeuropatias não-contíguas e de carácter primariamente axonal, nomeadamente: sensitivo-motora do nervo Mediano esquerdo moderada a grave; sensitiva do nervo Cubital direito de gravidade moderada e sensitivo-motora do nervo Femoral direito (incluindo nervo Safeno) moderada a grave. Todos os restantes nervos estudados não mostraram achados patológicos Concluiu-se presença de Mononeuritis multiplex.
Analiticamente com eosinofilia $\left(6700 \mathrm{~mm}^{3}, 37 \%\right)$, proteína C-reactiva e velocidade de sedimentação aumentadas $(70 \mathrm{mg} / \mathrm{L}$ e $65 \mathrm{~mm} / 1^{\text {ah }}$, respectivamente), ECA negativo, sem elevação dos marcadores de necrose miocárdica e função renal normal sem eritrocitúria e sem proteinúria. Estudo imunológico com ANCA-MP0 de $83 \mathrm{UI} / \mathrm{mL}$ (valor de referência $<5 \mathrm{Ul} / \mathrm{mL}$ ) e factor reumatóide, ANA e perfil ENA negativos. Serologias VIH, VHC, VHB, HSV e Borrelia burgdorferi negativas. Electrocardiograma e ecocardiograma transtorácico sem alterações.

A tomografia computorizada (TC) torácica mostrou bronquiectasias cilíndricas dispersas bilateralmente, sem se definir nódulos nem infiltrados, e a TC dos seios perinasais confirmou a existência de pólipos nasais, sem destruição osteocartilagínea.

Fez biópsia das lesões purpúricas que mostrou necrose fibrinóide com infiltrado inflamatório com predomínio de neutrófilos e eosinófilos, e estudo por imunofluorescência directa compatível com vasculite leucocitoclástica (Fig. 2). A biópsia da mucosa do septo nasal mostrou exsudado fibrinoleucocitário com numerosos eosinófilos e necrose eosinofílica.

Reúne 5 de 6 critérios de diagnóstico da ACR (asma; eosinofilia periférica $>10 \%$; mononeuropatia múltipla; sinusite; vasculite com eosinófilos extravasculares) e cumpre a definição de CHCC pelo que foi assumido o diagnóstico de EGPA.

Na indução terapêutica fez pulsos de ciclosfosfamida (3 pulsos de $15 \mathrm{mg} / \mathrm{Kg}$ em intervalos de 2 semanas e 1 pulso a cada 3 semanas durante 6 meses). Simultaneamente iniciou corticoterapia (3 pulsos de metilprednisolona 500mg e posteriormente prednisolona $1 \mathrm{mg} / \mathrm{kg} / \mathrm{dia})$.

Ao final de um ano de evolução sob corticoterapia em redução progressiva e azatioprina como terapêutica de manutenção houve resolução das queixas sensitivas e das lesões cutâneas, e meIhoria das alterações da marcha a permitir a marcha autónoma. Analiticamente já sem elevação dos marcadores inflamatórios e ANCA negativo.

Figura 1. Púrpura palpável no tornozelo esquerdo.

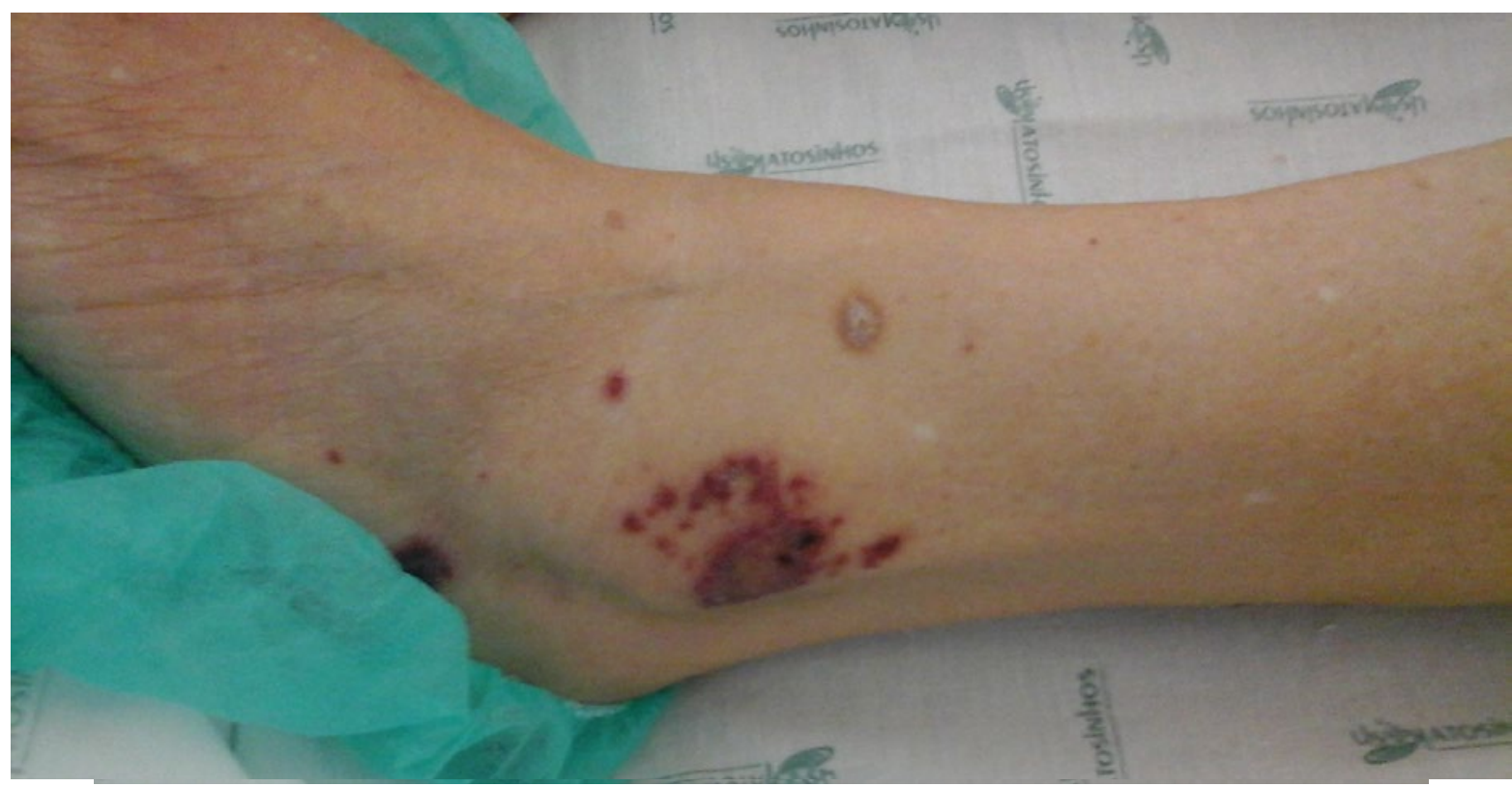




\section{Discussão}

A Granulomatose Eosinofílica com Poliangeíte é uma doença sistémica envolvendo geralmente mais do que um órgão ao longo do curso da doença. Na fase inicial os sintomas geralmente são inespecíficos e a identificação de padrões de apresentação clínica é fundamental para um diagnóstico precoce. Por exemplo, no caso descrito, asma de novo em idade adulta com polipose nasal e sinusite deve criar a suspeita, no entanto, o diagnóstico geralmente só é realizado na fase vasculítica, sendo a vasculite dos nervos periféricos um dos locais preferenciais e mais precocemente envolvidos na EGPA. Comparativamente às restantes vasculites associadas ao ANCA, a neuropatia periférica na EGPA parece ser mais frequente e o número de nervos envolvidos também é maior ${ }^{9-11}$. Existe relação entre a neuropatia periférica e 0 aparecimento de lesões cutâneas, pelo que ocorrência simultânea deve alertar para o diagnóstico. A observação na biópsia de vasculite necrotizante permanece como gold standard para o diagnóstico e a existência de numerosos eosinófilos no infiltrado leucocitário sugere EGPA. A presença de granulomas é rara e não é necessária ${ }^{1,13}$. A positividade do ANCA complementa o diagnóstico, mas está ausente em cerca de $50 \%$ dos casos e não é critério de exclusão $0^{3,4}$. Pesquisar o ANCA utilizando simultaneamente diferentes métodos (ELISA e IFE) aumenta a sensibilidade e especificidade, e está aconselhado quando a suspeita é alta ${ }^{14}$.

A vasculite neuropática nos doentes com vasculite sistémica está associada a baixa qualidade de vida, a recuperação é lenta e por vezes apenas parcial ${ }^{15}$. 0 diagnóstico precoce e 0 tratamento adequado permitem prevenir comorbilidades e diminuir a mortalidade, nomeadamente reduzir o dano neurológico e consequentemente melhorar a qualidade de vida. Neste contexto está aconselhado como tratamento de indução na mononeuropatia múltipla aguda 0 uso de corticoesteróides em associação com ciclofosfamida ${ }^{12,13}$.

Este caso clínico ilustra a importância do reconhecimento do padrão mononeuropático múltiplo de lesão axonal da neuropatia periférica na apresentação desta entidade, que pode ser irreversivelmente incapacitante se houver atraso no início do tratamento, tendo ajudado de forma considerável a orientação da investigação e integração dos achados clínicos e paraclínicos para ser estabelecido 0 diagnóstico de EGPA.
Figura 2. No exame histológico da biópsia da pele observa-se necrose fibrinóide das paredes vasculares e infiltrado inflamatório com eosinófilos.

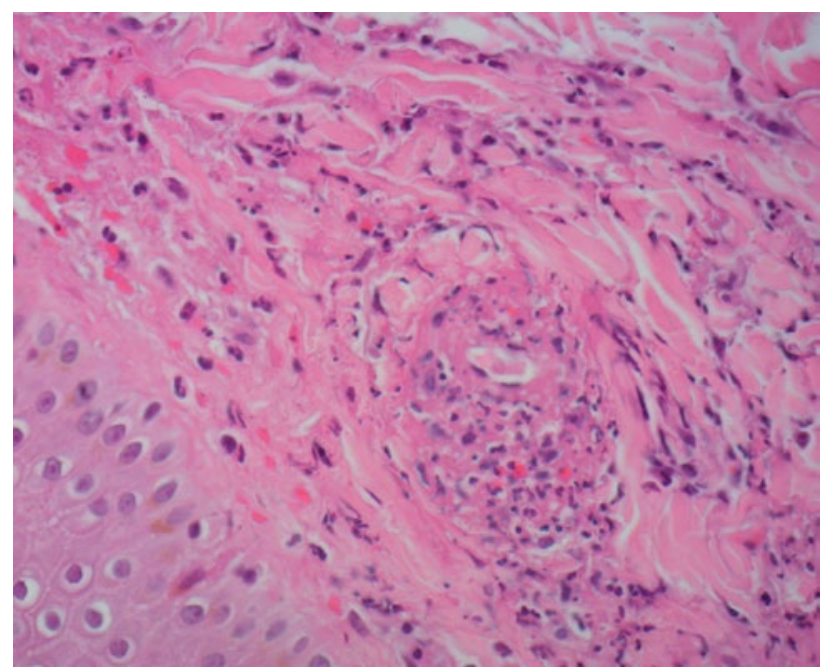

\section{Referências}

1. Jennette JC, Falk RJ, Bacon PA, Basu N, Cid MC, Ferrario F, et al. 2012 Revised International Chapel Hill Consensus Nomenclature of Vasculitides. Arthritis Rheum. 2013;65:1-11

2. Masi AT, Hunder GG, Lie JT, Michel BA, Bloch DA, Arend WP, et al. The American College of Rheumatology 1990 criteria for the classification of Churg-Strauss syndrome (allergic granulomatosis and angiitis). Arthritis Rheum. 1990;33:1094-1100.

3. Comarmond C, Pagnoux C, Khellaf M, Cordier JF, Hamidou M, Viallard JF, et al. Eosinophilic Granulomatosis With Polyangiitis (Churg-Strauss): Clinical Characteristics and Long-Term Followup of the 383 Patients Enrolled in the French Vasculitis Study Group Cohort. Arthritis Rheum. 2013;65:270-281.

4. Sada KE, Amano K, Uehara R, Yamamura M, Arimura Y, Nakamura Y, et al. A nationwide survey on the epidemiology and clinical features of eosinophilic granulomatosis with polyangiitis (Churg-Strauss) in Japan. Mod Rheumatol. 2014;24:640-644.

5. Mohammad AJ, Jacobsson LT, Mahr AD, Sturfelt G, Segelmark M. Prevalence of Wegener's granulomatosis, microscopic polyangiitis, polyarteritis nodosa and Chur$\mathrm{g}$-Strauss syndrome within a defined population in southern Sweden. Rheumatology (Oxford). 2007;46:1329-1337.

6. Reinhold-Keller E, Herlyn K, Wagner-Bastmeyer R, Gross W. Stable Incidence of Primary Systemic Vasculitides Over Five Years: Results From the German Vasculitis Register. Arthritis Rheum. 2005;53:93-99.

7. Mukhtyar C, Flossmann O, Hellmich B, Bacon P, Cid M, Cohen-Tervaert JW, et al. Outcomes from studies of antineutrophil cytoplasm antibody associated vasculitis: a systematic review by the European League Against Rheumatism systemic vasculitis task force. Ann Rheum Dis. 2008;67:1004-10.

8. Keogh K, Specks U. Churg-Strauss Syndrome: Clinical Presentation, Antineutrophil Cytoplasmic Antibodies, and Leukotriene Receptor Antagonists. Am J Med 2003;115:284-290.

9. Wolf J, Schmitt V, Palm F, Grau AJ, Bergner R. Peripheral neuropathy as initial manifestation of primary systemic vasculitides. J Neurol. 2013;260:1061-1070.

10. Wolf J, Bergner R, Mutallib S, Buggle F, Grau AJ. Neurologic complications of Churg-Strauss syndrome - a prospective monocentric study. Eur J Neurol. 2010;17:582-588.

11. Santos-Pinheiro F, Li Y. Eosinophlic Granulomatosis With Polyangiitis (Churg-Strauss Syndrome) Presenting With Polyneuropathy-A Case Series. J Clin Neuromuscul Dis. 2015;16:125-130.

12. Ntatsali $E$, Carruthers D, Chakravarty K, D'Cruz D, Harper L, Jayne D, et al. BSR and BHPR guideline for the management of adults with ANCA-associated vasculitis. Rheumatology. 2014;53:2306-2309.

13. Yates M, Watts RA, Bajema IM, Cid MC, Crestani B, Hauser T, et al. EULAR/ERA-EDTA recommendations for the management of ANCA-associated vasculitis. Ann Rheum Dis. 2016;75:1583-1594.

14. Choi H, Liu S, Merkel P, Colditz G, Niles J. Diagnostic performance of antineutrophil cytoplasmic antibody tests for idiopathic vasculitides: metaanalysis with a focus on antimyeloperoxidase antibodies. J Rheumatol. 2001;28(7):1584-90.

15. Walsh M, Mukhtyar C, Mahr A, Herlyn K, Luqmani R, Merkel PA, et al. Health-related quality of life in patients with newly diagnosed antineutrophil cytoplasmic antibody-associated vasculitis. Arhtritis Care Res. 2011; 63:1055-1061. 